\title{
Article \\ Estimation of Floor Response Spectra for Self-Centering
Structural Systems with Flag-Shaped Hysteretic Behavior
}

\author{
Binod Kumar Shrestha (D, Anil C. Wijeyewickrema *, Hiroki Miyashita and Niraj Malla
}

check for

updates

Citation: Shrestha, B.K.;

Wijeyewickrema, A.C.; Miyashita, H.;

Malla, N. Estimation of Floor

Response Spectra for Self-Centering

Structural Systems with Flag-Shaped

Hysteretic Behavior. Buildings 2022,

12, 167. https://doi.org/10.3390/

buildings12020167

Academic Editor: Emanuele Brunesi

Received: 17 January 2022

Accepted: 1 February 2022

Published: 3 February 2022

Publisher's Note: MDPI stays neutral with regard to jurisdictional claims in published maps and institutional affiliations.

Copyright: (C) 2022 by the authors. Licensee MDPI, Basel, Switzerland. This article is an open access article distributed under the terms and conditions of the Creative Commons Attribution (CC BY) license (https:// creativecommons.org/licenses/by/ $4.0 /)$.
Department of Civil and Environmental Engineering, Tokyo Institute of Technology, 2-12-1 O-okayama, Meguro-ku, Tokyo 152-8552, Japan; shrestha.b.ac@m.titech.ac.jp (B.K.S.); miyashita.h.ac@m.titech.ac.jp (H.M.); nirajmalla67@gmail.com (N.M.)

* Correspondence: wijeyewickrema.a.aa@m.titech.ac.jp

\begin{abstract}
Spectral floor-acceleration demands are necessary for the seismic design of accelerationsensitive non-structural components (NSCs). Existing studies to estimate floor response spectra (FRS) using empirical equations are based on elasto-plastic and stiffness degrading hysteretic behavior of the primary structure. In the present study, the FRS for self-centering (SC) structural systems with flag-shaped hysteretic behavior under far-fault ground motions are investigated. The FRS and dynamic amplification factor (DAF) are obtained from nonlinear response history analysis (NLRHA) of SC structural systems with flag-shaped hysteretic behavior. An equation to estimate the FRS is proposed and verified by carrying out NLRHA using a different set of far-fault ground motions. The equation to estimate FRS is shown to predict floor acceleration demands with very good accuracy.
\end{abstract}

Keywords: dynamic amplification factor; flag-shaped hysteretic behavior; floor response spectra; non-structural components; self-centering system

\section{Introduction}

The adoption of seismic design has greatly reduced the damage to the structural elements of buildings. However, damage to secondary structural elements and non-structural components (NSCs) can lead to huge economic losses, due to associated loss of functionality of important facilities and business downtime after a major earthquake (see for eg., EERI [1], Villaverde [2], Dhakal et al. [3], Devin and Fanning [4], Wang et al. [5]). Although existing building codes such as Eurocode 8 [6] and ASCE 7-16 [7] provide expressions to determine the acceleration demand for the estimation of seismic design force for acceleration-sensitive NSCs, several studies have shown that the peak floor acceleration and floor response spectra (FRS) estimated from such codes are not accurate (see for e.g., Sullivan et al. [8], Vukobratovic and Fajfar [9], Aragaw and Calvi [10], Kazantzi et al. [11], Vukobratovic et al. [12]).

Estimation of FRS using empirical equations based on a single-degree-of-freedom (SDOF) system for the primary structure have been reported in previous studies. Oropeza et al. [13] considered primary structures with an elasto-plastic and modified Takeda hysteretic model, while Sullivan et al. [8] also considered primary structures using a modified Takeda hysteretic model. Vukobratovic and Fajfar [14] used the equation of Yasui et al. [15] in the pre- and post-resonance region and an empirically developed expression in the resonance region for primary structures with an elasto-plastic and stiffness degrading model to estimate FRS. Welch and Sullivan [16] modified the equation developed by Sullivan et al. [8] to estimate the FRS.

Several studies have also extended the approach to estimate the FRS using empirical equations based on SDOF systems to multi-degree-of-freedom (MDOF) systems. For instance, the estimation of FRS for reinforced concrete (RC) frame systems by Calvi and Sullivan [17], Vukobratovic and Fajfar [18], and Merino et al. [19], for RC walls by Welch and Sullivan [16] and Vukobratovic and Ruggieri [20], and for base rocking wall buildings by Aragaw and Calvi [10]. 
The excellent seismic performance of self-centering (SC) structural systems with flag-shaped hysteretic behavior have been reported previously (see for e.g., Kurama [21], Smith et al. [22], Belleri et al. [23], Buddika and Wijeyewickrema [24], Shrestha et al. [25]). In the present study, the FRS for SC structural systems with flag-shaped hysteretic behavior under far-fault ground motions are investigated. The FRS and dynamic amplification factor (DAF) are obtained from nonlinear response history analysis (NLRHA) of SC structural systems with flag-shaped hysteretic behavior. An equation to estimate the FRS is proposed and verified by carrying out NLRHA using a different set of far-fault ground motions.

\section{Self-Centering (SC) SDOF System with Flag-Shaped Hysteretic Behavior, Ground Motion Records, and Numerical Modeling}

The force-displacement relationship of the self-centering (SC) SDOF system with flag-shaped hysteretic behavior, which is the primary structure is shown in Figure 1. The nonlinear response history analysis (NLRHA) of the SC flag-shaped SDOF system is carried out with the following parameters: initial vibration period $T_{p}=0.1 \mathrm{~s}, 0.3 \mathrm{~s}, 0.5 \mathrm{~s}, 0.75 \mathrm{~s}$, $1.0 \mathrm{~s}, 1.5 \mathrm{~s}, 2.0 \mathrm{~s}$; response reduction factor $R=1$, 1.5, 2, 3, 4, 5, 6; post-yield stiffness ratio $\alpha=5 \%$; energy dissipation parameter $\beta=0 \%-100 \%$ (increments of $20 \%$ ) and viscous damping ratio $\xi_{p}=5 \%$. Even though $R=6$ or 7 is used for the design of self-centering structural systems using the force-based design method (Smith et al. [22], Buddika and Wijeyewickrema [24]), a wide range of $R$ values are adopted in this study. This is done so that the developed FRS in Section 4 can also be used with the direct displacement-based design method, where the $R$ value depends on the target displacement (Priestley et al. [26], Yang and $\mathrm{Lu}$ [27]). It is noted that for SC flag-shaped SDOF systems, a viscous damping ratio $\xi_{p}=5 \%$ has been used in previous studies (see for e.g., Rahgozar et al. [28], Zhang et al. [29], Dong et al. [30]). The non-structural component (NSC), which is the secondary structure, is represented by an elastic SDOF system with vibration period $T_{S}=0.1 \mathrm{~s}-4.0 \mathrm{~s}$ (increments of $0.1 \mathrm{~s})$; and viscous damping ratio $\xi_{s}=5 \%$.

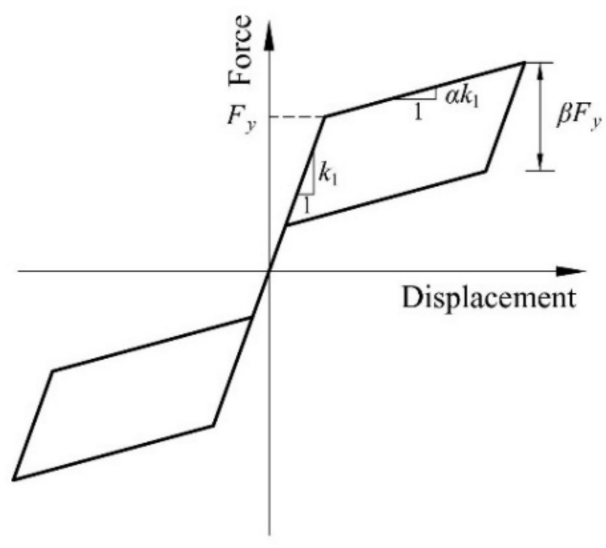

Figure 1. The force-displacement relationship of the self-centering (SC) SDOF system with flagshaped hysteretic behavior. Note: $k_{1}=$ initial stiffness; $\alpha=$ post-yield stiffness ratio; $\beta=$ energy dissipation parameter; $F_{y}=$ yield strength.

For NLRHA, 11 far-fault ground motions are considered from the 22 far-fault ground motion set of FEMA P695 (Table A-4A, FEMA [31]) and given in Table 1.

In the present study, the NLRHA is carried out using OpenSees [32]. The SC flagshaped SDOF system (primary structure) is modeled using a zero-length element with the SelfCentering material model. The NSC (secondary structure) is represented by an elastic SDOF system and modeled using a zero-length element. The numerical integration of the equations of motion is accomplished using the Newmark constant average acceleration $\operatorname{method}\left(\beta_{N}=0.25, \gamma_{N}=0.5\right)$. 
Table 1. Far-fault ground motions used for the NLRHA (Table A-4A, FEMA [31]).

\begin{tabular}{|c|c|c|c|c|c|c|c|c|c|}
\hline $\begin{array}{l}\text { EQ. } \\
\text { No. }\end{array}$ & Event & Year & Station & Fault Type & $M_{w}$ & $R_{r u p}(\mathbf{k m})$ & $\begin{array}{c}\text { PGA } \\
\text { Component } 1\end{array}$ & $\begin{array}{c}\text { PGA } \\
\text { Component } 2\end{array}$ & $\begin{array}{l}\bar{v}_{s} \\
(\mathrm{~m} / \mathrm{s})\end{array}$ \\
\hline 1 & Northridge & 1994 & Beverly Hills - Mulhol & Thrust & 6.7 & 17.2 & 0.42 & 0.52 & 356 \\
\hline 2 & Northridge & 1994 & Canyon Country-WLC & Thrust & 6.7 & 12.4 & 0.41 & 0.48 & 309 \\
\hline 3 & Duzce, Turkey & 1999 & Bolu & Strike-slip & 7.1 & 12.0 & 0.73 & 0.82 & 326 \\
\hline 4 & Hector Mine & 1999 & Hector & Strike-slip & 7.1 & 11.7 & 0.27 & 0.34 & 685 \\
\hline 5 & Imperial Valley & 1979 & Delta & Strike-slip & 6.5 & 22.0 & 0.24 & 0.35 & 275 \\
\hline 6 & Imperial Valley & 1979 & El Centro Array \#11 & Strike-slip & 6.5 & 12.5 & 0.36 & 0.38 & 196 \\
\hline 7 & Kobe, Japan & 1995 & Nishi-Akashi & Strike-slip & 6.9 & 7.1 & 0.51 & 0.50 & 609 \\
\hline 8 & Kobe, Japan & 1995 & Shin-Osaka & Strike-slip & 6.9 & 19.2 & 0.24 & 0.21 & 256 \\
\hline 9 & Kocaeli, Turkey & 1999 & Duzce & Strike-slip & 7.5 & 15.4 & 0.31 & 0.36 & 276 \\
\hline 10 & Kocaeli, Turkey & 1999 & Arcelik & Strike-slip & 7.5 & 13.5 & 0.22 & 0.15 & 523 \\
\hline 11 & Landers & 1992 & Yermo Fire Station & Strike-slip & 7.3 & 23.6 & 0.24 & 0.15 & 354 \\
\hline
\end{tabular}

\section{Floor Response Spectra and Dynamic Amplification Factor from Nonlinear Response History Analysis (NLRHA)}

\subsection{Floor Response Spectra}

The floor response spectra for self-centering (SC) structural systems with flag-shaped hysteretic behavior are determined using the following procedure:

(a) The NLRHA of the prescribed self-centering (SC) SDOF system with flag-shaped hysteretic behavior (primary structure), for the set of ground motion records and determination of the total floor acceleration response history for each ground motion record. Here, the total floor acceleration response history is the sum of the floor acceleration response history relative to the ground and the ground acceleration response history.

(b) Linear RHA of the elastic SDOF system (secondary structure), using the set of total floor acceleration response histories determined from step (a), to generate floor response spectra.

(c) Calculation of the mean floor response spectrum.

The mean normalized floor response spectra (FRS), i.e., $A_{s} / A_{p}$, where $A_{p}, A_{s}$ are the peak acceleration demands of the primary structure and secondary structure, respectively, are calculated for the structural parameters stated in Section 2. The ratio $A_{s} / A_{p}$ is also referred to as the dynamic amplification factor $(D A F)$. In Figures 2 and 3 the mean normalized floor response spectra are shown only for $T_{p}=0.5 \mathrm{~s}, 1.0 \mathrm{~s}$, respectively. It can be observed that when the primary structure is elastic, i.e., $R=1$, a single peak of the mean normalized FRS at $T_{s} / T_{p}=1$ can be observed. When $R>1$, the primary structure behaves inelastically and rather than a single peak, the maximum value of the mean normalized FRS remains nearly constant over a wide period range and forms a spectral plateau. Moreover, the width of the spectral plateau increases with increase in $R$ and decrease in $\beta$, which is due to the higher ductility demand on the primary structure. In most cases, the peak value of mean normalized FRS increases when $R$ changes from 1 to 2 and then decreases for $R>2$.

To investigate the effect of $\beta$ more clearly, the mean normalized FRS are shown for a SC system with $R=6, T_{p}=0.5 \mathrm{~s}, 1.0 \mathrm{~s}$, and $\beta=0 \%, 20 \%, \ldots, 100 \%$ in Figure 4 . The results show that the mean normalized FRS decreases when $\beta$ increases. A wider spectral plateau is observed with decrease in $\beta$. 

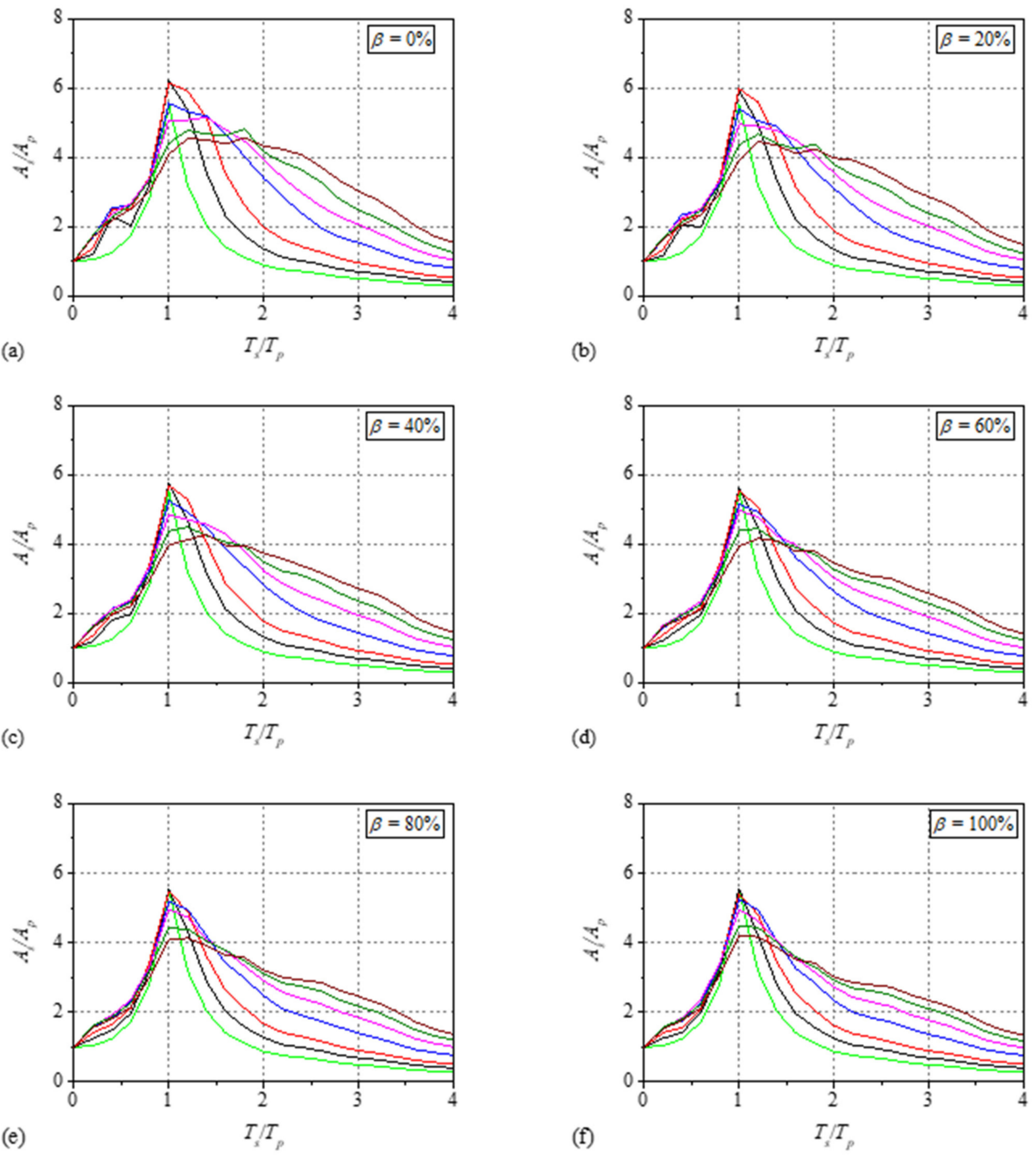

(e)

\begin{tabular}{rll|}
$-R=1$, & $-R=1.5, \quad-R=2, \quad-R=3$, \\
$R=4$, & $-R=5$, & $-R=6$
\end{tabular}

Figure 2. Mean normalized floor response spectra for SC systems with $T_{p}=0.5 \mathrm{~s}$, post-yield stiffness ratio $\alpha=5 \%$; viscous damping ratio $\xi_{p}=5 \%$; and a secondary structure with viscous damping ratio $\xi_{s}=5 \%$ : (a) $\beta=0 \%$; (b) $\beta=20 \%$; (c) $\beta=40 \%$; (d) $\beta=60 \%$; (e) $\beta=80 \%$; and (f) $\beta=100 \%$. 

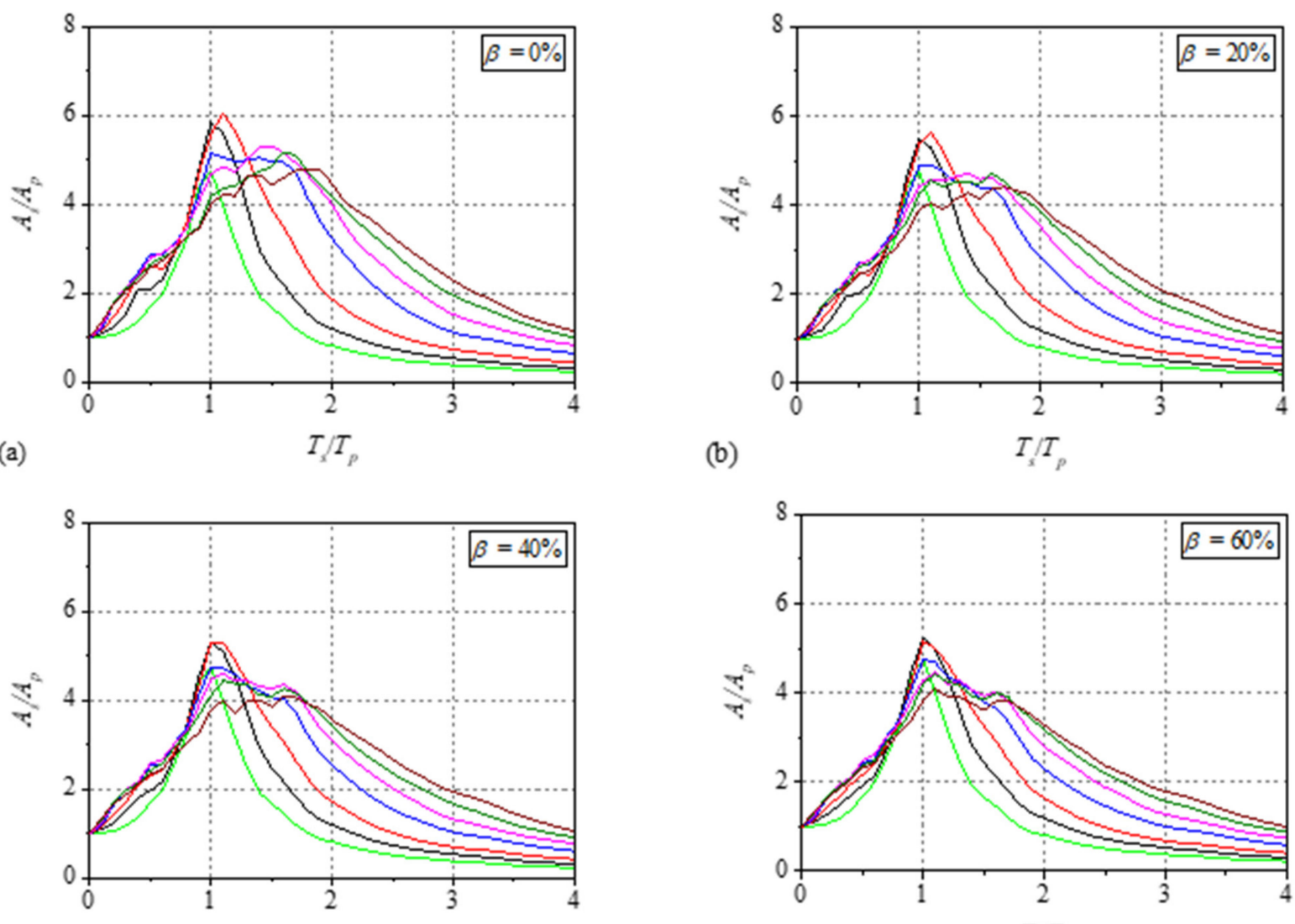

(c)

$T_{1} / T_{p}$
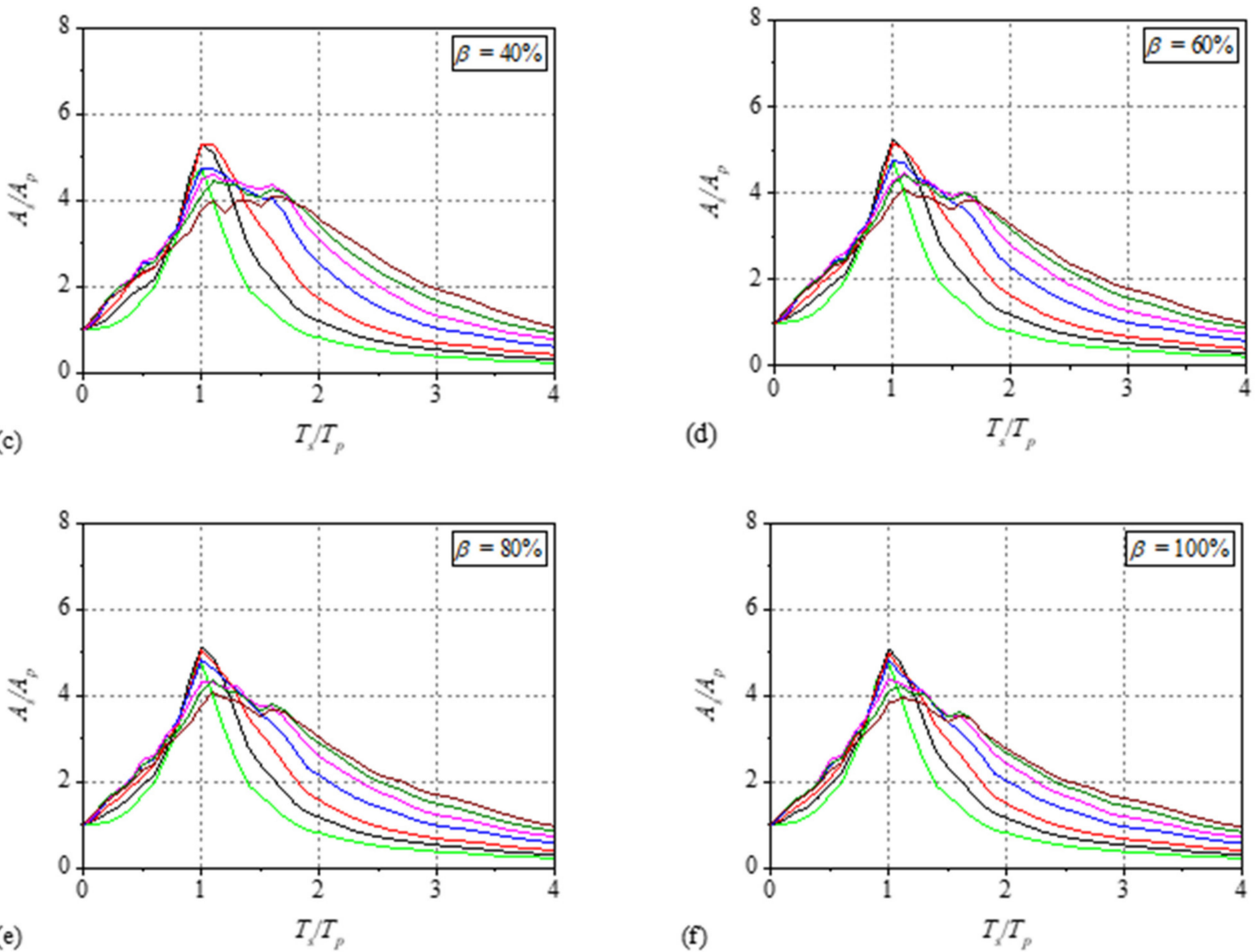

(e)

$T_{s} / T_{p}$

$\begin{array}{rll}-R=1, & -R=1.5, & -R=2, \\ R=4, & -R=5, & -R=3,\end{array}$

Figure 3. Mean normalized floor response spectra for SC systems with $T_{p}=1.0 \mathrm{~s}$, post-yield stiffness ratio $\alpha=5 \%$; viscous damping ratio $\xi_{p}=5 \%$; and a secondary structure with viscous damping ratio $\xi_{s}=5 \%$ : (a) $\beta=0 \%$; (b) $\beta=20 \%$; (c) $\beta=40 \%$; (d) $\beta=60 \%$; (e) $\beta=80 \%$; and (f) $\beta=100 \%$. 


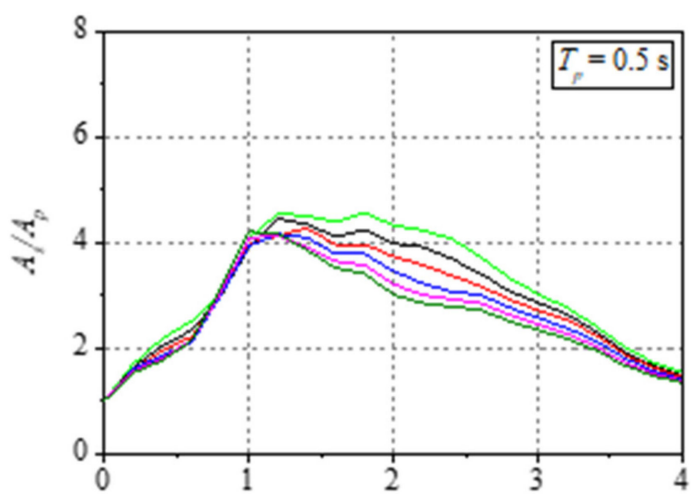

(a)
$T / T_{p}$

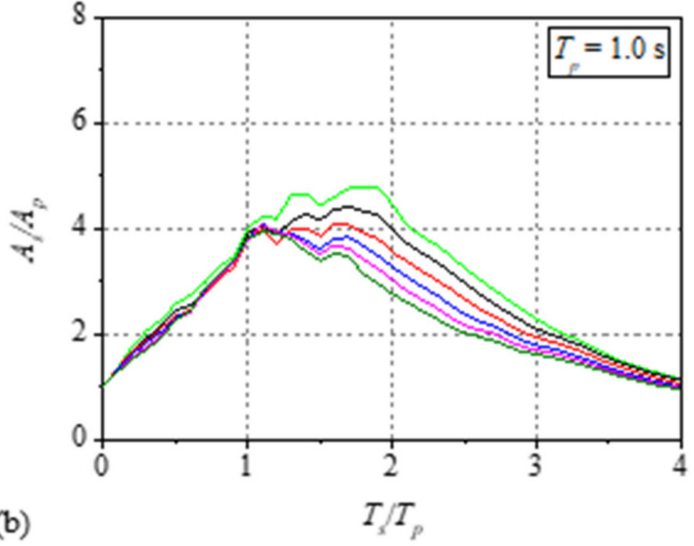

(b)

Figure 4. Effect of energy dissipation parameter $\beta$ on mean normalized floor response spectra for a SC system with $R=6$, post-yield stiffness ratio $\alpha=5 \%$; viscous damping ratio $\xi_{p}=5 \%$; and a secondary structure with viscous damping ratio $\xi_{s}=5 \%$ : (a) $T_{p}=0.5 \mathrm{~s}$; and (b) $T_{p}=1.0 \mathrm{~s}$.

\subsection{Maximum Dynamic Amplification Factor $D A F_{\text {max }}$}

Figure 5 shows the maximum values of mean normalized FRS for $T_{p}=0.1 \mathrm{~s}, 0.3 \mathrm{~s}$, $0.5 \mathrm{~s}, 0.75 \mathrm{~s}, 1.0 \mathrm{~s}, 1.5 \mathrm{~s}, 2.0 \mathrm{~s}$, also referred to as maximum dynamic amplification factor $D A F_{\max }$. Note that this $D A F_{\max }$ will be used in the equation to estimate FRS developed in Section 4. It is observed that with increase in $T_{p}, D A F_{\max }$ increases for $T_{p} \leq 0.5 \mathrm{~s}$, and remains nearly constant for $T_{p}>0.5 \mathrm{~s}$ and $R>1.0$. It is also observed that the $D A F_{\text {max }}$ decreases with increasing $\beta$. Based on the results of NLRHA shown in Figure 5, an empirical equation to estimate the $D A F_{\max }$ is developed by carrying out nonlinear least-square regression analysis, where the regression coefficients are obtained using the Levenberg-Marquardt algorithm (Bates and Watts [33]) available in SPSS [34]. The equation for $D A F_{\text {max }}$ is,

$$
D A F_{\max }\left(T_{p}, R, \beta ; \xi_{s}\right)= \begin{cases}\frac{1}{\sqrt{\xi_{s}}}\left(a T_{p}^{b}+c\right), & R=1 \\ \frac{0.15(1+\beta)^{-2.6}+0.85}{\sqrt{\xi_{s}}}\left(a T_{p}^{b}+c\right), & R>1\end{cases}
$$

where $a, b$, and $c$ are constant coefficients determined from nonlinear regression analysis, separately for each $R$ and given in Table 2. Note that in the present study, the viscous damping ratio of the secondary structure $\xi_{s}=5 \%$ (see Section 2 ). The equation is given for elastic $(R=1)$ and inelastic $(R>1)$ primary structures. For verification purposes, in Figure 6 the $D A F_{\max }$ obtained from Equation (1) are compared with the NLRHA results obtained using a different set of far-fault ground motions given in Table 3 . The $T_{p}, R, \alpha, \beta$, and $\xi_{p}$ of the primary structure defined in Section 2 are used for the verification. It can be seen that Equation (1) can estimate the $D A F_{\max }$ accurately from the NLRHA results for primary structures with different $T_{p}, R$, and $\beta$.

Table 2. Regression coefficients of the equation for $D A F_{\max }$.

\begin{tabular}{ccccccccc}
\hline Coefficients & $\boldsymbol{R}=\mathbf{1 . 0}$ & $\boldsymbol{R}=\mathbf{1 . 5}$ & $\boldsymbol{R}=\mathbf{2 . 0}$ & $\boldsymbol{R}=\mathbf{3 . 0}$ & $\boldsymbol{R}=\mathbf{4 . 0}$ & $\boldsymbol{R}=\mathbf{5 . 0}$ & $\boldsymbol{R}=\mathbf{6 . 0}$ \\
\hline$a$ & -0.020 & -0.001 & -0.013 & -0.021 & -0.017 & -0.019 & -0.018 \\
$b$ & -1.304 & -2.358 & -1.574 & -1.400 & -1.382 & -1.258 & -1.178 \\
$c$ & 1.259 & 1.330 & 1.350 & 1.260 & 1.175 & 1.108 & 1.043 \\
\hline
\end{tabular}



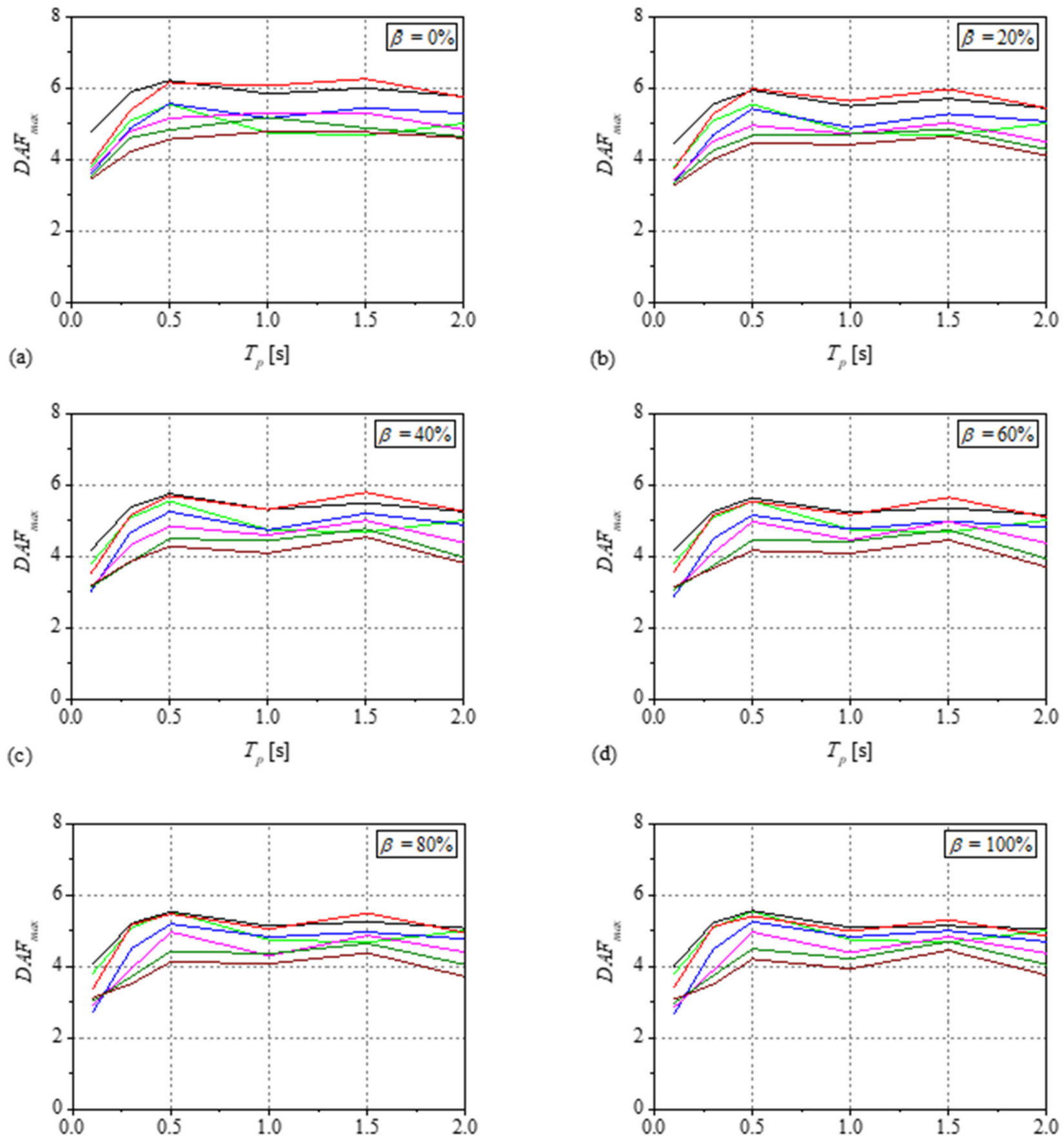

(e)

$T_{p}[\mathrm{~s}]$
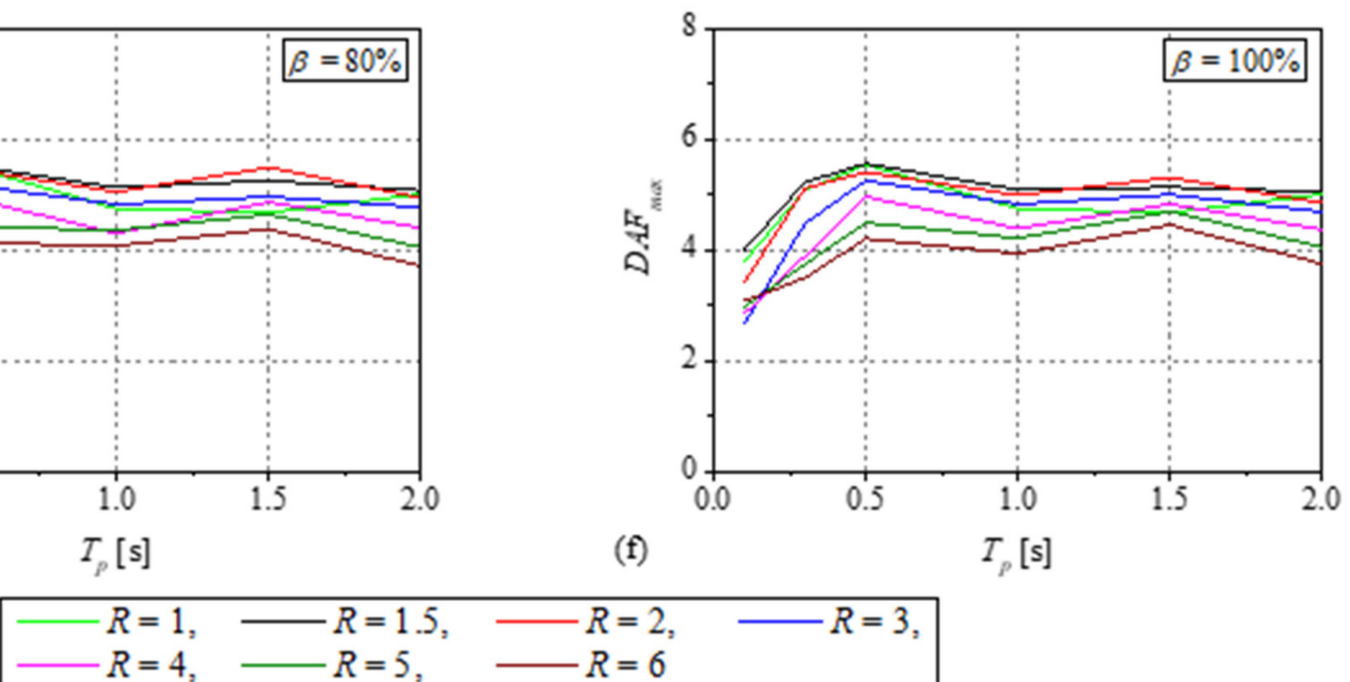

Figure 5. Maximum dynamic amplification factor $D A F_{\max }$ for a SC system with post-yield stiffness ratio $\alpha=5 \%$; viscous damping ratio $\xi_{p}=5 \%$; and a secondary structure with viscous damping ratio $\xi_{s}=5 \%$ : (a) $\beta=0 \%$; (b) $\beta=20 \%$; (c) $\beta=40 \%$; (d) $\beta=60 \%$; (e) $\beta=80 \%$; and (f) $\beta=100 \%$. 


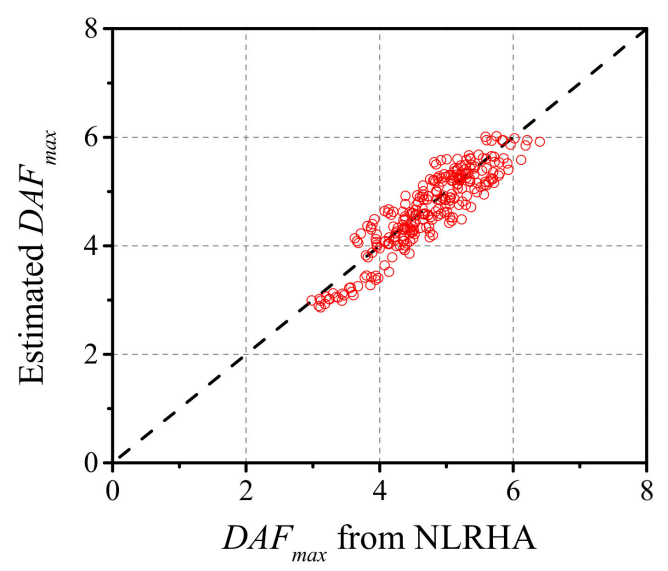

Figure 6. Comparison of the $D A F_{\max }$ from the NLRHA results with the estimated $D A F_{\max }$ from Equation (1).

Table 3. Far-fault ground motions used for the verification (Table A-4A, FEMA [31]) of DAF $F_{\max }$ (Equation (1)) and the proposed equation for FRS (Equation (5)).

\begin{tabular}{|c|c|c|c|c|c|c|c|c|c|}
\hline $\begin{array}{l}\text { EQ } \\
\text { No. }\end{array}$ & Event & Year & Station & Fault Type & $M_{w}$ & $R_{r u p}(\mathrm{~km})$ & $\begin{array}{c}\text { PGA } \\
\text { Component } 1\end{array}$ & $\begin{array}{c}\text { PGA } \\
\text { Compontent } 2\end{array}$ & $\begin{array}{c}\bar{v}_{s} \\
(\mathrm{~m} / \mathrm{s})\end{array}$ \\
\hline 1 & Landers & 1992 & Coolwater & Strike-slitd & 7.3 & 19.7 & 0.28 & 0.42 & 271 \\
\hline 2 & Loma tdrieta & 1989 & Capitola & Strike-slip & 6.9 & 15.2 & 0.53 & 0.44 & 289 \\
\hline 3 & Loma Prieta & 1989 & Gilroy Array \#3 & Strike-slip & 6.9 & 12.8 & 0.56 & 0.37 & 350 \\
\hline 4 & Manjil, Iran & 1990 & Abbar & Strike-slip & 7.4 & 12.6 & 0.51 & 0.50 & 724 \\
\hline 5 & Superstition Hills & 1987 & El Centro Imp. Co. & Strike-slip & 6.5 & 18.2 & 0.36 & 0.26 & 192 \\
\hline 6 & Superstition Hills & 1987 & Poe Road (temp) & Strike-slip & 6.5 & 11.2 & 0.45 & 0.30 & 208 \\
\hline 7 & Catde Mendocino & 1992 & Rio Dell Overpass & Thrust & 7.0 & 14.3 & 0.39 & 0.55 & 312 \\
\hline 8 & Chi-Chi, Taiwan & 1999 & CHY101 & Thrust & 7.6 & 10.0 & 0.35 & 0.44 & 259 \\
\hline 9 & Chi-Chi, Taiwan & 1999 & TCU045 & Thrust & 7.6 & 26.0 & 0.47 & 0.51 & 705 \\
\hline 10 & San Fernando & 1971 & LA - Hollywood Stor & Thrust & 6.6 & 22.8 & 0.21 & 0.17 & 316 \\
\hline 11 & Friuli, Italy & 1976 & Tolmezzo & Thrust & 6.5 & 15.8 & 0.35 & 0.31 & 425 \\
\hline
\end{tabular}

Note: $M_{w}=$ moment magnitude; PGA = peak ground acceleration; $R_{r u p}=$ distance from recording site to epicenter; $\bar{v}_{s}=$ average shear wave velocity.

\subsection{Post-Resonance Dynamic Amplification Factor $D A F_{p r}$}

The post-resonance dynamic amplification factor $D A F_{p r}$ will also be used in the equation to estimate the FRS proposed in Section 4. Considering the expression for $D A F_{\max }$ given in Equation (1) and the estimation of floor spectra by Welch and Sullivan [16], the equation for $D A F_{p r}$ is expressed by,

$$
D A F_{p r}\left(T_{p}, R, \beta ; T_{s}, \xi_{s}\right)= \begin{cases}\frac{1}{\sqrt{\left(1-\frac{T_{s}}{T_{e}}\right)^{2}+\xi_{s}}}\left(a T_{p}^{b}+c\right), & R=1 \\ \frac{0.15(1+\beta)^{-2.6}+0.85}{\sqrt{\left(1-\frac{T_{s}}{T_{e}}\right)^{2}+\xi_{s}}}\left(a T_{p}^{b}+c\right), & R>1\end{cases}
$$

where the effective period $T_{e}$ associated with the secant stiffness at peak response of the primary structure is given by,

$$
T_{e}\left(T_{p}, \alpha, \mu\right)=T_{p} \sqrt{\frac{\mu}{1+\alpha(\mu-1)}}
$$

(see Welch and Sullivan [16]), where $\alpha=$ post-yield stiffness ratio (taken as $5 \%$ in this study), and the ductility demand $\mu$ is computed using the equation for constant-strength inelastic displacement ratio $C_{R}$ given by Zhang et al. [29] for SC systems as, 


$$
\mu\left(T_{p}, R, \beta\right)=\left\{1+(R-1)^{0.515} \frac{0.184+0.119(1-\beta)^{1.173}}{T_{p} 1.478}\right\} R
$$

\section{Equation to Estimate Floor Response Spectra and Verification}

\subsection{Equation to Estimate FRS}

In the present study, the following equation is proposed to estimate the FRS for the primary structure as SC systems,

$$
\frac{A_{s}}{A_{p}}\left(T_{p}, R, \beta ; T_{s}, \xi_{s}\right)= \begin{cases}1+\frac{T_{s}}{T_{p}}\left(D A F_{\max }-1\right), & 0 \leq T_{s}<T_{p} \\ D A F_{\max }, & T_{p} \leq T_{s} \leq T_{e} \\ D A F_{p r}, & T_{s}>T_{e}\end{cases}
$$

Note that an equation of similar form was used by Sullivan et al. [8] for the estimation of FRS for well detailed RC structures.

The acceleration demand of the secondary structure increases linearly in the preresonance region $0 \leq T_{s}<T_{p}$, remains constant in the resonance region $T_{p} \leq T_{s} \leq T_{e}$ forming a spectral plateau, and decreases in the post-resonance region $T_{s}>T_{e}$. Note that the effective period $T_{e}$ increases with the higher inelastic deformation demand of the primary structure, i.e., increase in $R$ and decrease in $\beta$, which leads to an increase in the width of the spectral plateau.

\subsection{Verification of Proposed Equation to Estimate FRS}

For the verification, a primary structure which is a SC structural system with flagshaped hysteretic behavior, with initial vibration period $T_{p}=0.5 \mathrm{~s}, 1.0 \mathrm{~s}, 1.5 \mathrm{~s}$, response reduction factor $R=2,4,6$, post-yield stiffness ratio $\alpha=5 \%$; energy dissipation parameter $\beta=0 \%, 20 \%, \ldots, 100 \%$, and viscous damping ratio $\xi p=5 \%$; and a secondary structure with viscous damping ratio $\xi_{s}=5 \%$ is considered. It is noted that both the primary and secondary structures are modeled by SDOF systems.

Here, 11 far-fault ground motions are considered from the 22 far-fault ground motion set of FEMA P695 (Table A-4A, FEMA [31]) and given in Table 3. Note that these 11 far-fault ground motions are not the same ground motions used in Section 2.

The mean floor response spectra are determined from NLRHA using the procedure given in Section 3.1. The mean peak acceleration demand of the secondary structure $A_{s}$ obtained from Equation (5) and NLRHA are shown in Figures 7-9. The mean normalized peak acceleration demand of the secondary structure $A_{s} / A_{p}$ obtained from Equation (5) and NLRHA are shown in Appendix A. For $T_{p}=0.5 \mathrm{~s}, 1.0 \mathrm{~s}$, the $A_{s}$ estimated from Equation (5) slightly underestimates the peak acceleration demand of the secondary structure in the resonance region but is mostly conservative in the other regions. For $T_{p}=1.5 \mathrm{~s}$, the $A_{s}$ estimated from Equation (5) slightly underestimates the peak acceleration demand of the secondary structure in the post-resonance region but is mostly conservative in the other regions. It is also observed that the width of the spectral plateau with varying $R$ and $\beta$ can be well estimated from Equation (5). In general it can be concluded that the $A_{s}$ estimated from Equation (5) shows good accuracy when compared with NLRHA results.

\subsection{Comparison of the Proposed FRS with Existing Direct Methods}

The mean peak acceleration demand of the secondary structure $A_{s}$ obtained from Equation (5) of the present analysis and existing direct methods of Sullivan et al. [8] and Vukobratovic and Fajfar [14] are compared with the NLRHA results in Figure 10. The equations to estimate the FRS using existing direct methods are given in Appendix B. For the comparison, a primary structure with flag-shaped hysteretic behavior, with initial vibration period $T_{p}=1.0 \mathrm{~s}$, response reduction factor $R=2$; post-yield stiffness ratio $\alpha=5 \%$; energy dissipation parameter $\beta=0 \%, 20 \%, \ldots, 100 \%$, and viscous damping ratio $\xi_{p}=5 \%$; and a secondary structure with viscous damping ratio $\xi_{s}=5 \%$ is considered. 

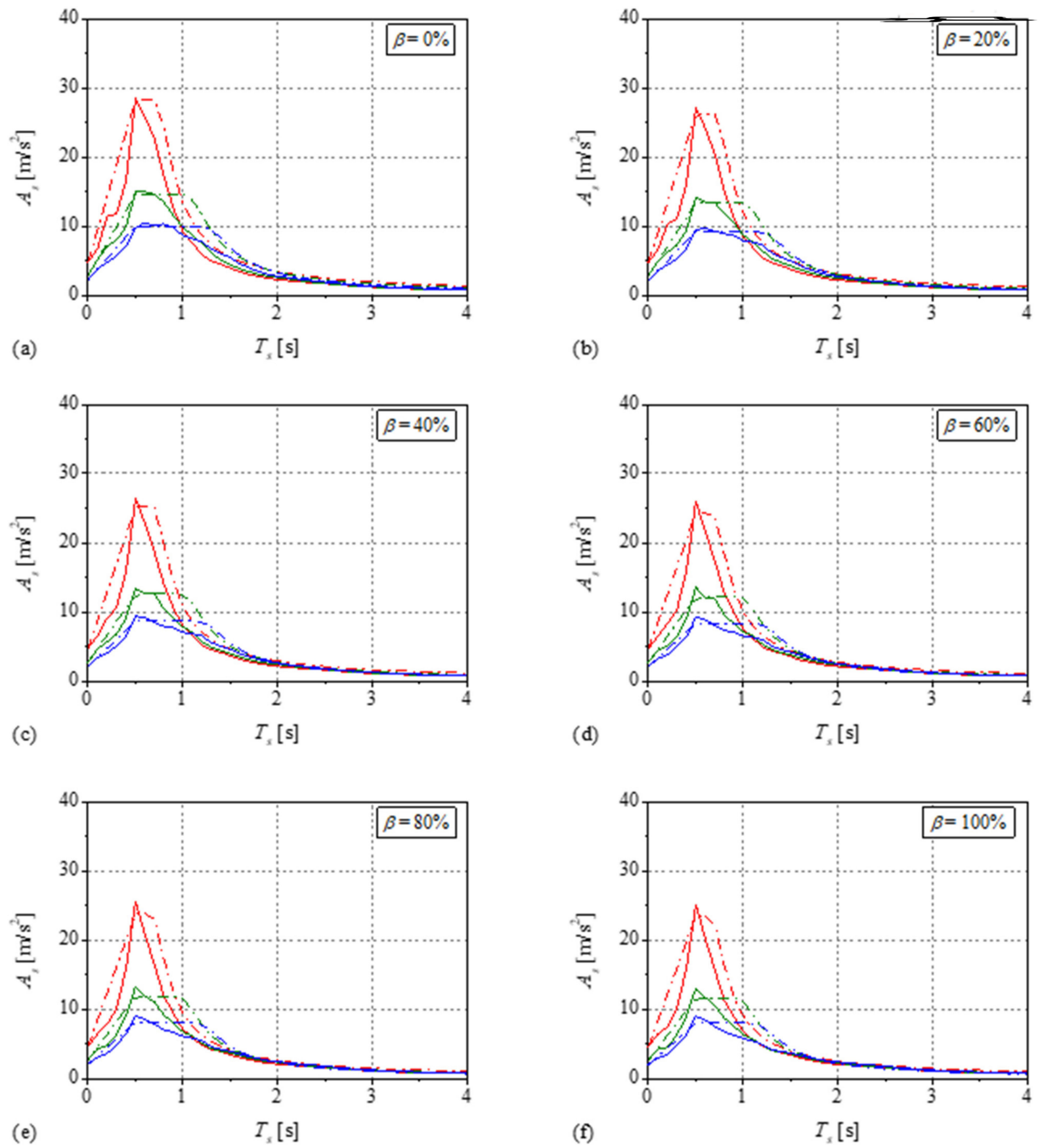

\begin{tabular}{|lccc|}
\hline$R$ & 2 & 4 & 6 \\
Eq. (5) - Present A nalysis & $-\cdot \cdot \cdot \cdot$ & $-\cdot-\cdot \cdot$ & $-\cdot \cdot \cdot \cdot$ \\
NLRHA & - & - & - \\
\hline
\end{tabular}

Figure 7. Comparison of the mean floor response spectra from Equation (5) and NLRHA for a primary structure with initial vibration period $T_{p}=0.5 \mathrm{~s}$, post-yield stiffness ratio $\alpha=5 \%$; viscous damping ratio $\xi_{p}=5 \%$; and a secondary structure with viscous damping ratio $\xi_{s}=5 \%$ : (a) $\beta=0 \%$; (b) $\beta=20 \%$; (c) $\beta=40 \%$; (d) $\beta=60 \%$; (e) $\beta=80 \%$; and (f) $\beta=100 \%$. 

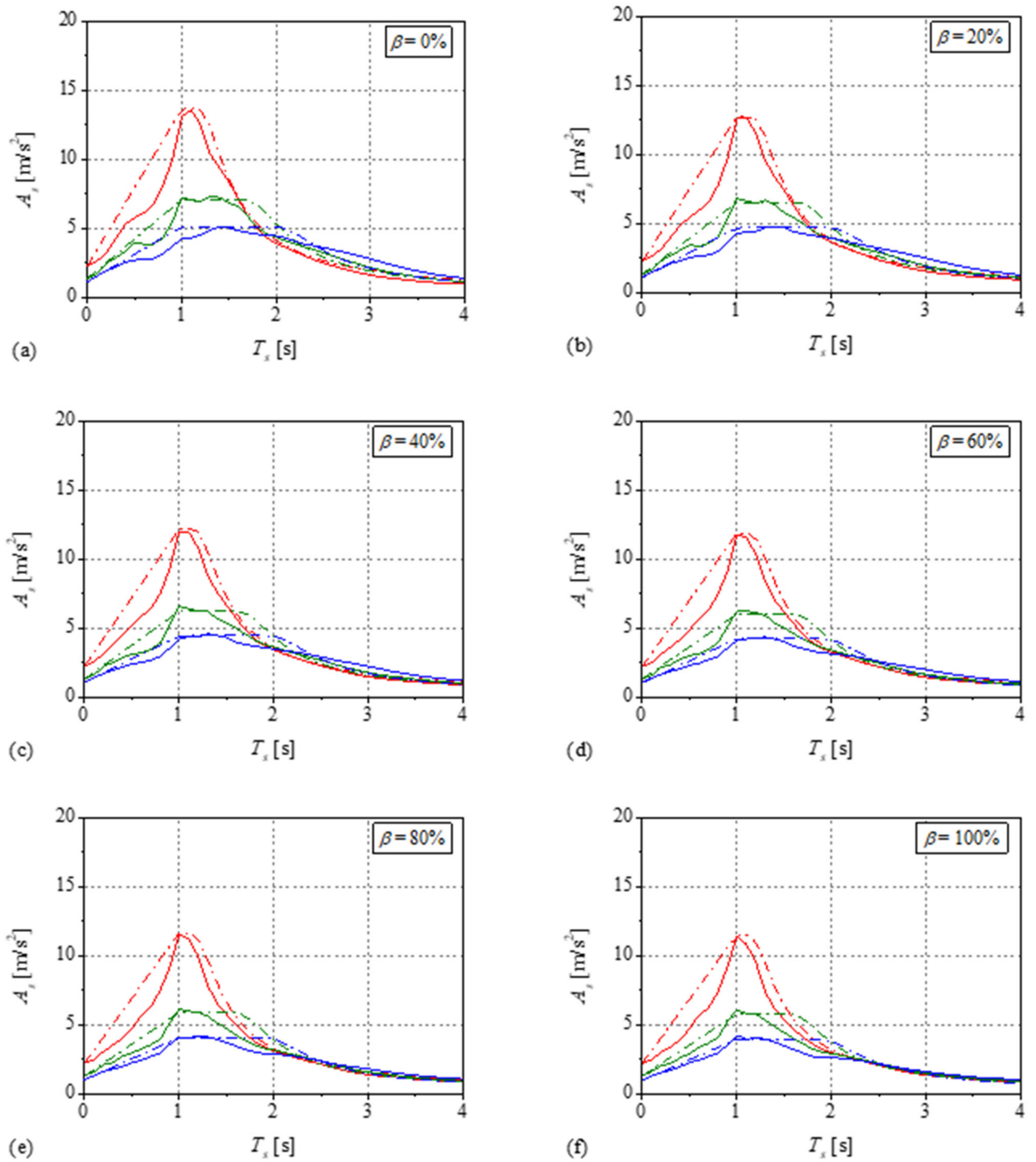

\begin{tabular}{|lccc|}
\hline$R$ & 2 & 4 & 6 \\
Eq. (5) - Present Analysis & $-\cdot-\cdot$ & $-\cdot-\cdot$ & $-\cdot-\cdot \cdot$ \\
NLRHA & - & - & - \\
\hline
\end{tabular}

Figure 8. Comparison of the mean floor response spectra from Equation (5) and NLRHA for a primary structure with initial vibration period $T_{p}=1.0 \mathrm{~s}$, post-yield stiffness ratio $\alpha=5 \%$; viscous damping ratio $\xi_{p}=5 \%$; and a secondary structure with viscous damping ratio $\xi_{s}=5 \%$ : (a) $\beta=0 \%$; (b) $\beta=20 \%$; (c) $\beta=40 \%$; (d) $\beta=60 \%$; (e) $\beta=80 \%$; and (f) $\beta=100 \%$. 

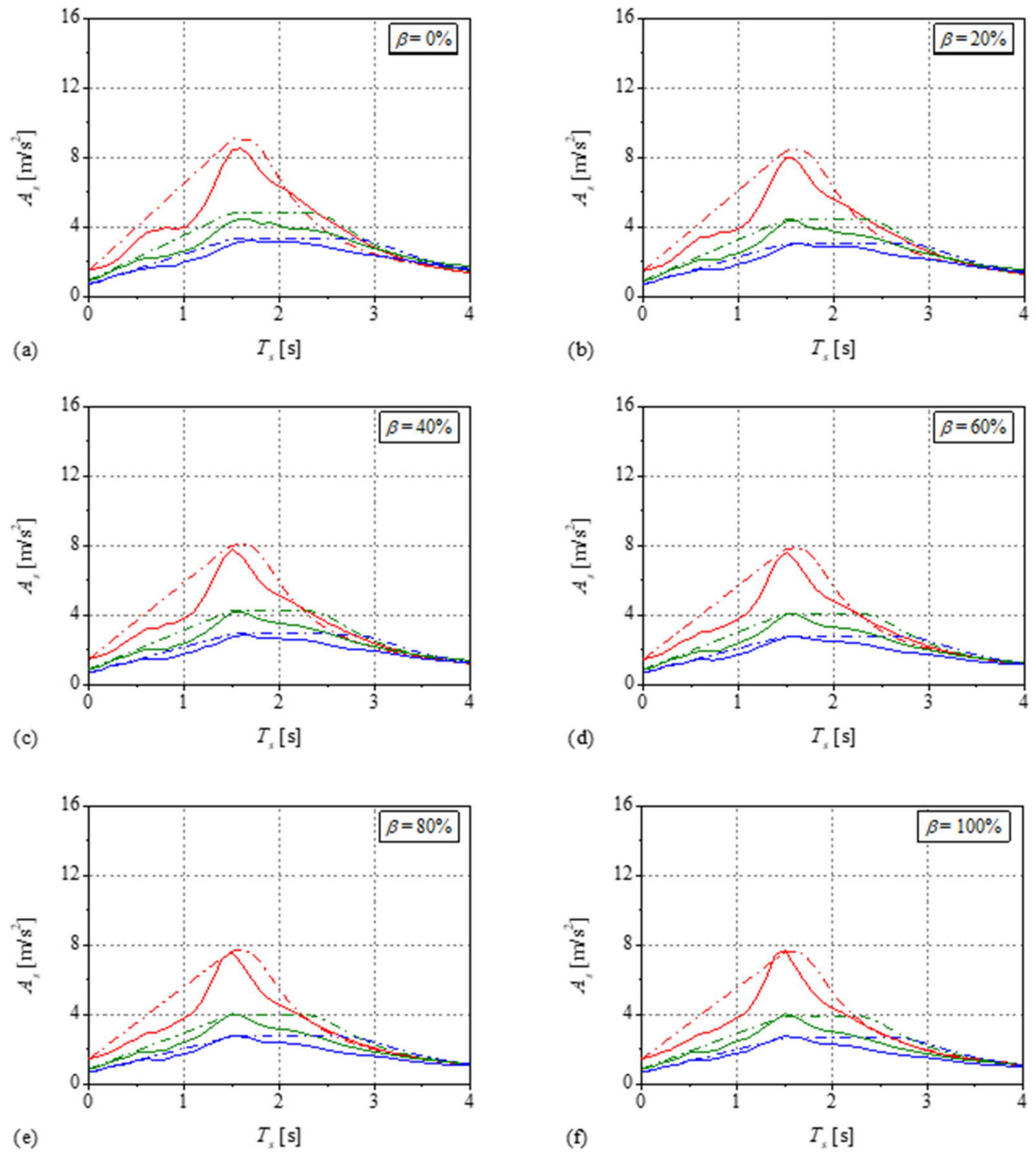

\begin{tabular}{|lccc|}
\hline$R$ & 2 & 4 & 6 \\
Eq. (5) - Present A nalysis & $-\cdot-\cdot \cdot$ & $-\cdot \cdot \cdot \cdot$ & $-\cdot \cdot \cdot \cdot$ \\
NLRHA & - & - & - \\
\hline
\end{tabular}

Figure 9. Comparison of the mean floor response spectra from Equation (5) and NLRHA for a primary structure with initial vibration period $T_{p}=1.5 \mathrm{~s}$, post-yield stiffness ratio $\alpha=5 \%$; viscous damping ratio $\xi_{p}=5 \%$; and a secondary structure with viscous damping ratio $\xi_{s}=5 \%$ : (a) $\beta=0 \%$; (b) $\beta=20 \%$; (c) $\beta=40 \%$; (d) $\beta=60 \%$; (e) $\beta=80 \%$; and (f) $\beta=100 \%$. 

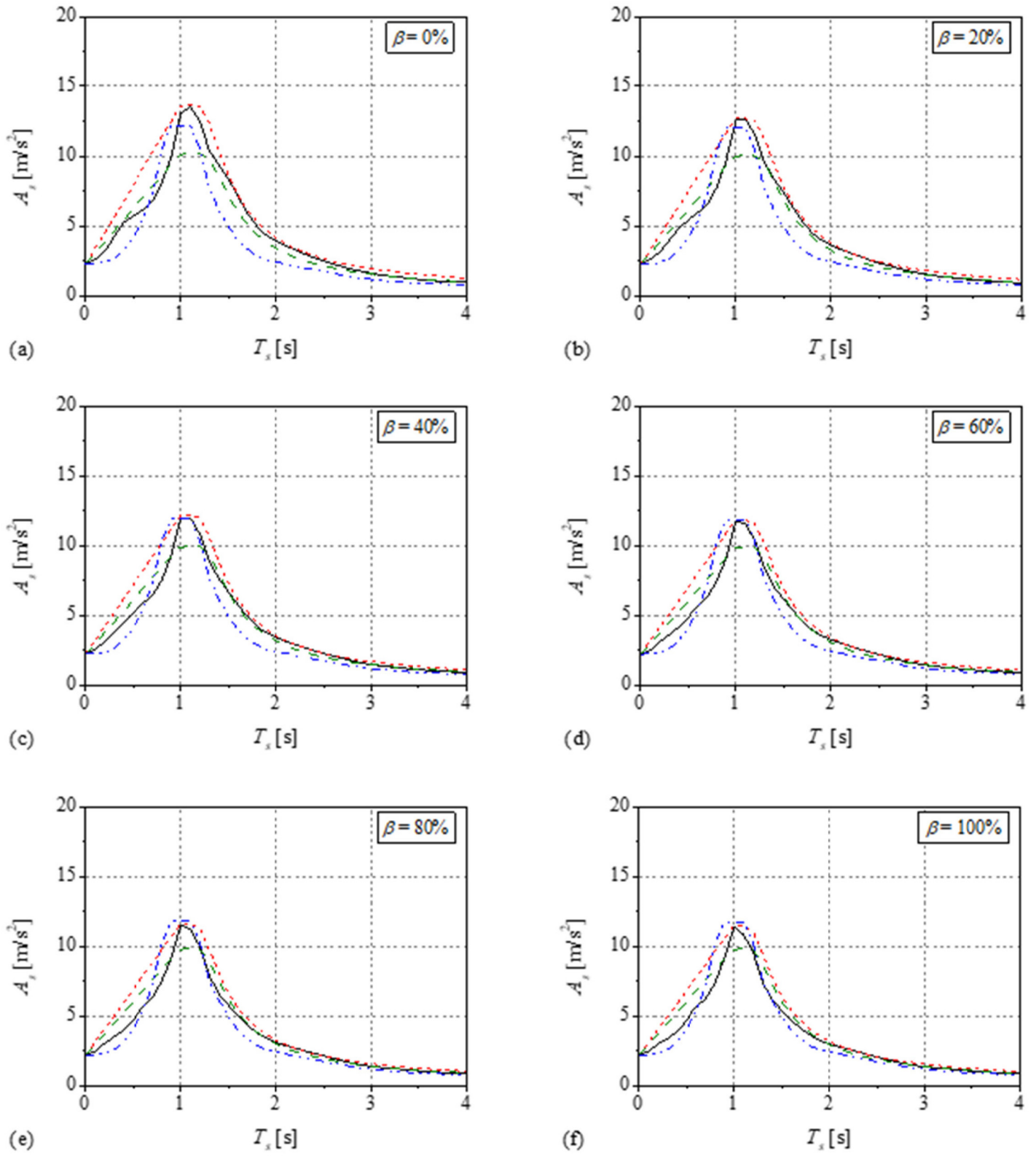

…- Eq. (5) - Present Analysis, - NLRHA,

Figure 10. Comparison of the mean floor response spectra from Equation (5) of the present analysis, Sullivan et al. [8], Vukobratovic and Fajfar [14], and NLRHA for a primary structure with initial vibration period $T_{p}=1.0 \mathrm{~s}$, response reduction factor $R=2$; post-yield stiffness ratio $\alpha=5 \%$; viscous damping ratio $\xi_{p}=5 \%$; and a secondary structure with viscous damping ratio $\xi_{s}=5 \%$ : (a) $\beta=0 \%$; (b) $\beta=20 \%$; (c) $\beta=40 \%$; (d) $\beta=60 \%$; (e) $\beta=80 \%$; and (f) $\beta=100 \%$. Note: The methods of Sullivan et al. [8] and Vukobratovic and Fajfar [14] are for primary structures with modified Takeda and elasto-plastic hysteretic behavior, respectively.

It is observed that the $A_{s}$ estimated from Equation (5) of present analysis provides a good estimate in the resonance region and slightly overestimates in the other regions (see Figure 10). The method of Sullivan et al. [8] slightly overestimates in pre-resonance region but underestimates in the resonance region. Moreover, in the post-resonance region, $A_{s}$ is underestimated for $\beta \leq 20 \%$, but shows good accuracy for $\beta>20 \%$. The method of Vukobratovic and Fajfar [14] underestimates $A_{s}$ in the pre-resonance region for $T_{S}<0.6 \mathrm{~s}$. In the resonance region, underestimation of $A_{s}$ for $\beta \leq 20 \%$, and overestimation of $A_{s}$ for $\beta>20 \%$ is observed. Furthermore, $A_{s}$ is underestimated in the post-resonance region. 
Note that the proposed equation to compute FRS is developed for SC flag-shaped SDOF system and show dependency with $\beta$. As a result, the estimated $A_{s}$ from Equation (5) of the present analysis shows good accuracy than the existing direct methods when compared with NLRHA results.

\section{Conclusions}

In this study, the floor response spectra (FRS) for self-centering (SC) structural systems with flag-shaped hysteretic behavior is investigated using nonlinear response history analysis (NLRHA), and an equation to estimate the FRS is proposed. In particular, a primary structure with post-yield stiffness ratio $\alpha=5 \%$; viscous damping ratio $\xi_{p}=5 \%$; and a secondary structure with viscous damping ratio $\xi_{s}=5 \%$ is considered. The proposed equation is then verified using a different set of far-fault ground motions. Based on the study, the following conclusions can be drawn:

1. The effect of the primary structure initial vibration period $T_{p}$, response reduction factor $R$, and energy dissipation parameter $\beta$ on the FRS is studied. A single peak was observed on the mean normalized FRS for $R=1$, but for $R>1$, the maximum value of the mean normalized FRS is nearly constant over a wide period range and forms a spectral plateau. The width of the spectral plateau increases with increase in $R$ and decrease in $\beta$, which is due to the higher ductility demand on the primary structure. In addition, the peak value of mean normalized FRS increases when $R$ changes from 1 to 2 and then decreases for $R>2$. The reduction in the mean normalized FRS was observed with increase in $\beta$. With increase in $T_{p}$, the maximum dynamic amplification factor $D A F_{m a x}$, increases for $T_{p} \leq 0.5 \mathrm{~s}$, and remains nearly constant for $T_{p}>0.5 \mathrm{~s}$ and $R>1$.

2. An empirical equation for $D A F_{\max }$ which can be used to estimate the acceleration demand in the resonance region is developed. This equation showed good accuracy when compared with NLRHA results. In addition for the post-resonance region, an equation to estimate the dynamic amplification factor $D A F_{p r}$ is also obtained.

3. An equation to estimate the FRS for SC systems with flag-shaped hysteretic behavior is proposed using the $D A F_{\text {max }}$ and the $D A F_{p r}$. The equation to estimate FRS is then validated using a different set of far-fault ground motions. It was observed that the equation to estimate FRS for SC systems with flag-shaped hysteretic behavior showed good accuracy when compared with the NLRHA results.

The results of this study are useful for the seismic design of acceleration-sensitive non-structural components (NSCs).

The equation to estimate FRS developed in the present study is based on SC structural systems with flag-shaped hysteretic behavior with a primary structure with post-yield stiffness ratio $\alpha=5 \%$ and viscous damping ratio $\xi_{p}=5 \%$, and a secondary structure with viscous damping ratio $\xi_{s}=5 \%$. Since the damping ratio of the secondary structure strongly influences the FRS, more damping ratios of secondary structures $\xi_{s}$ should be investigated and the accuracy of the proposed equation should be examined. Future studies, should also investigate the effect of post-yield stiffness ratio $\alpha$, and the viscous damping ratio of the primary structure $\xi_{p}$, on the FRS for SC structural systems with flag-shaped hysteretic behavior.

Author Contributions: Conceptualization, B.K.S., A.C.W., H.M. and N.M.; methodology, B.K.S., A.C.W., H.M. and N.M.; validation, B.K.S., A.C.W., H.M. and N.M.; writing-original draft preparation, B.K.S., A.C.W., H.M. and N.M.; writing-review and editing, B.K.S., A.C.W. and N.M. All authors have read and agreed to the published version of the manuscript.

Funding: This research received no external funding.

Institutional Review Board Statement: Not applicable.

Informed Consent Statement: Not applicable.

Data Availability Statement: Not applicable. 
Acknowledgments: The authors B.K.S. and N.M. gratefully acknowledge Monbukagakusho (Ministry of Education, Culture, Sports, Science, and Technology, Japan) scholarships for graduate students.

Conflicts of Interest: The authors declare no conflict of interest.

\section{Appendix A. Comparison of the Normalized Floor Response Spectra}

The normalized FRS from Equation (5) and NLRHA results for a primary structure with $T_{p}=0.5 \mathrm{~s}, 1.0 \mathrm{~s}, 1.5 \mathrm{~s}$; post-yield stiffness ratio $\alpha=5 \%$; viscous damping ratio $\xi_{p}=5 \%$; and a secondary structure with viscous damping ratio $\xi_{s}=5 \%$ are shown in Figures A1-A3
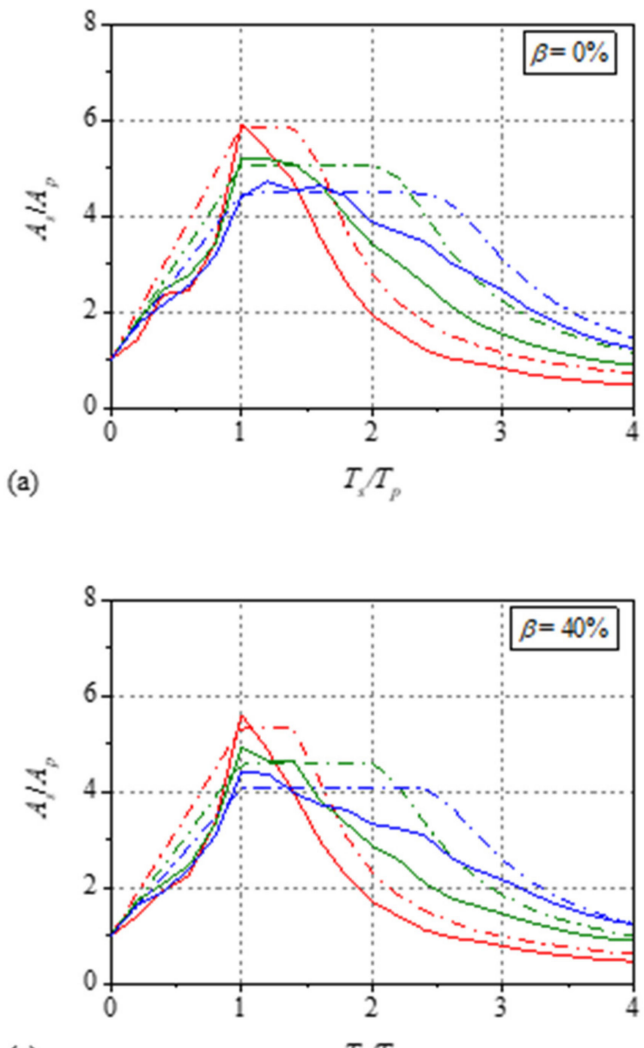

(c)

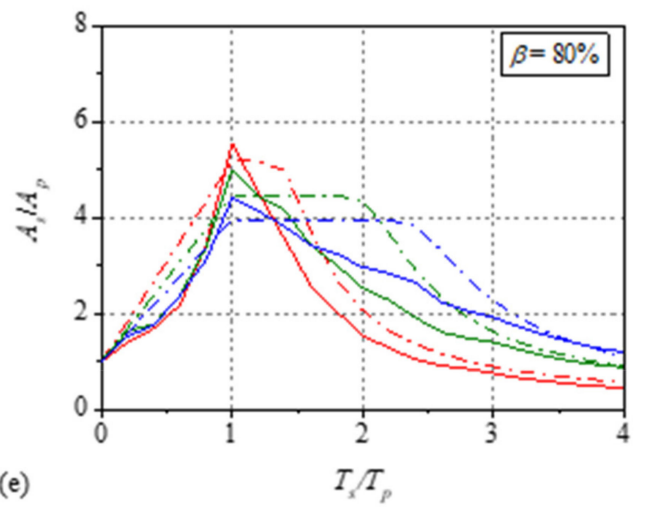

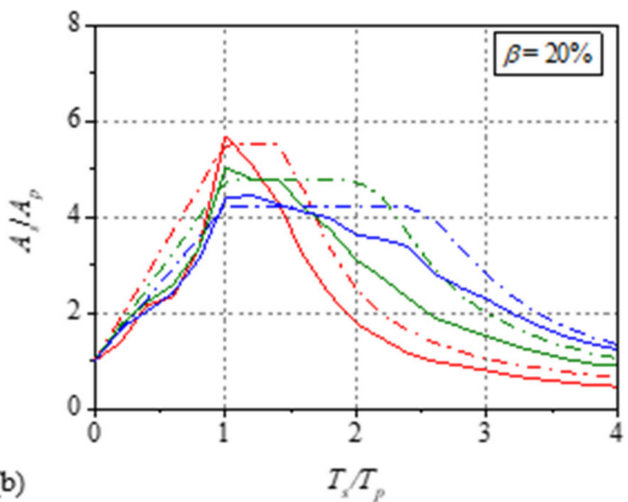
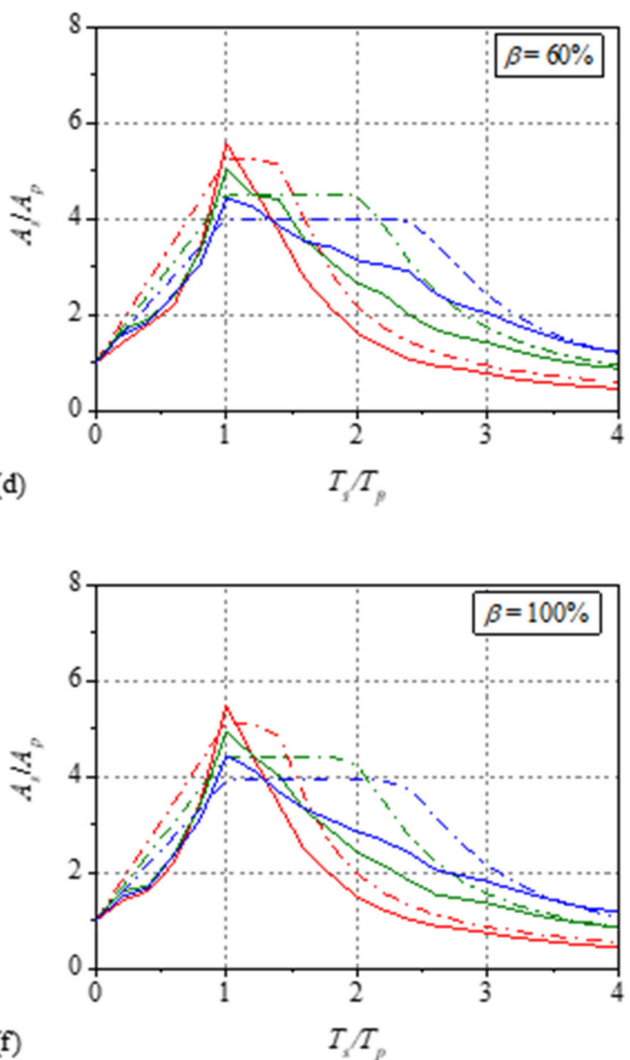

(f)

\begin{tabular}{ccc}
2 & 4 & 6 \\
$-\cdot-\cdot \cdot$ & $-\cdot-\cdot \cdot$ & $-\cdot-\cdot \cdot$ \\
- & - & - \\
\hline
\end{tabular}

Figure A1. Comparison of the mean normalized floor response spectra from Equation (5) and for a primary structure with initial vibration period $T_{p}=0.5 \mathrm{~s}$ : (a) $\beta=0 \%$; (b) $\beta=20 \%$; (c) $\beta=40 \%$; (d) $\beta=60 \%$; (e) $\beta=80 \%$; and (f) $\beta=100 \%$. 

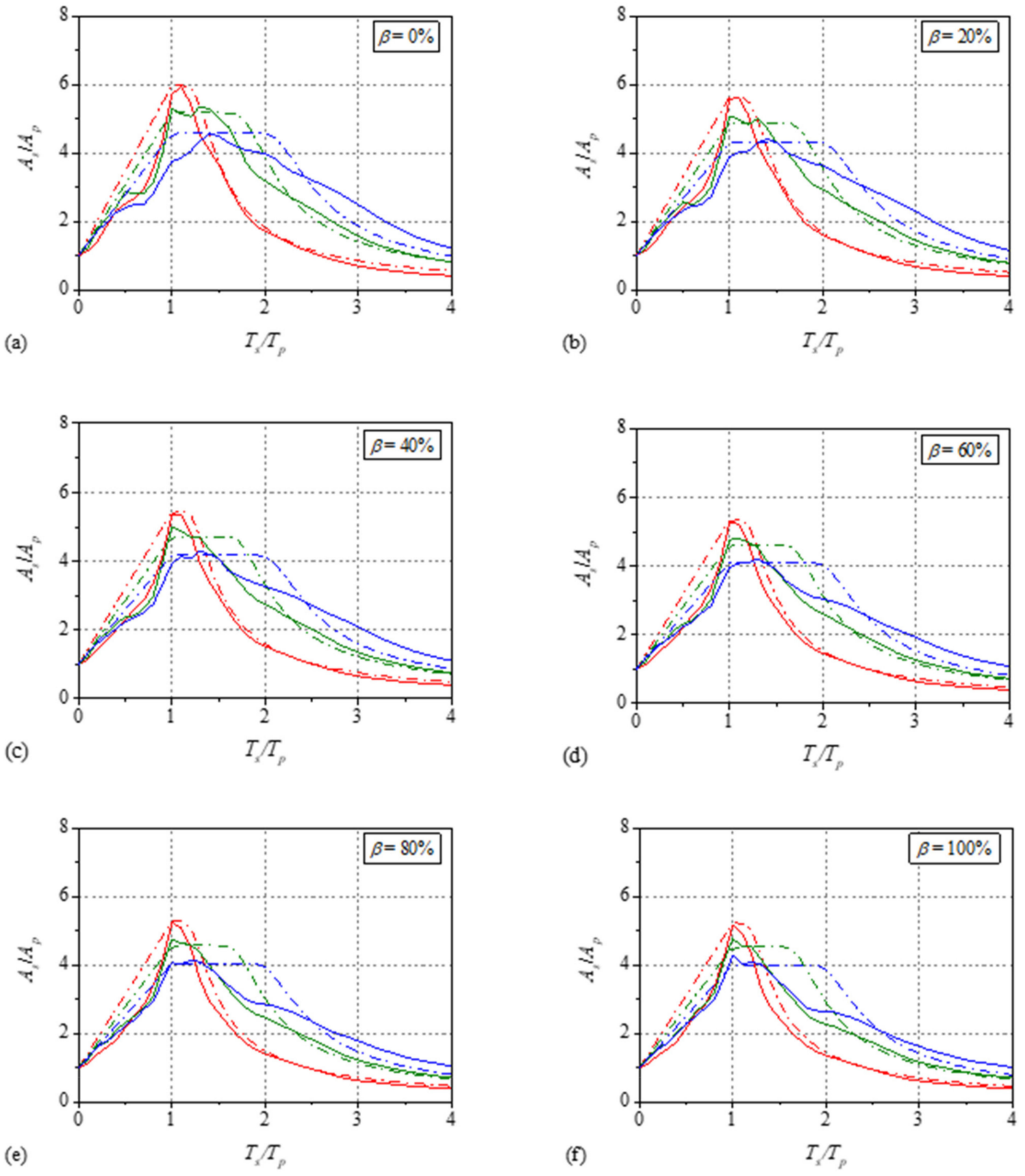

\begin{tabular}{|lccc|}
\hline$R$ & 2 & 4 & 6 \\
Eq. (5) - Present A nalysis & $-\cdot-\cdot \cdot$ & $-\cdot-\cdot \cdot$ & $-\cdot \cdot-\cdot \cdot$ \\
NLRHA & - & & - \\
\hline
\end{tabular}

Figure A2. Comparison of the mean normalized floor response spectra from Equation (5) and for a primary structure with initial vibration period $T_{p}=1.0 \mathrm{~s}$ : (a) $\beta=0 \%$; (b) $\beta=20 \%$; (c) $\beta=40 \%$; (d) $\beta=60 \%$; (e) $\beta=80 \%$; and (f) $\beta=100 \%$. 

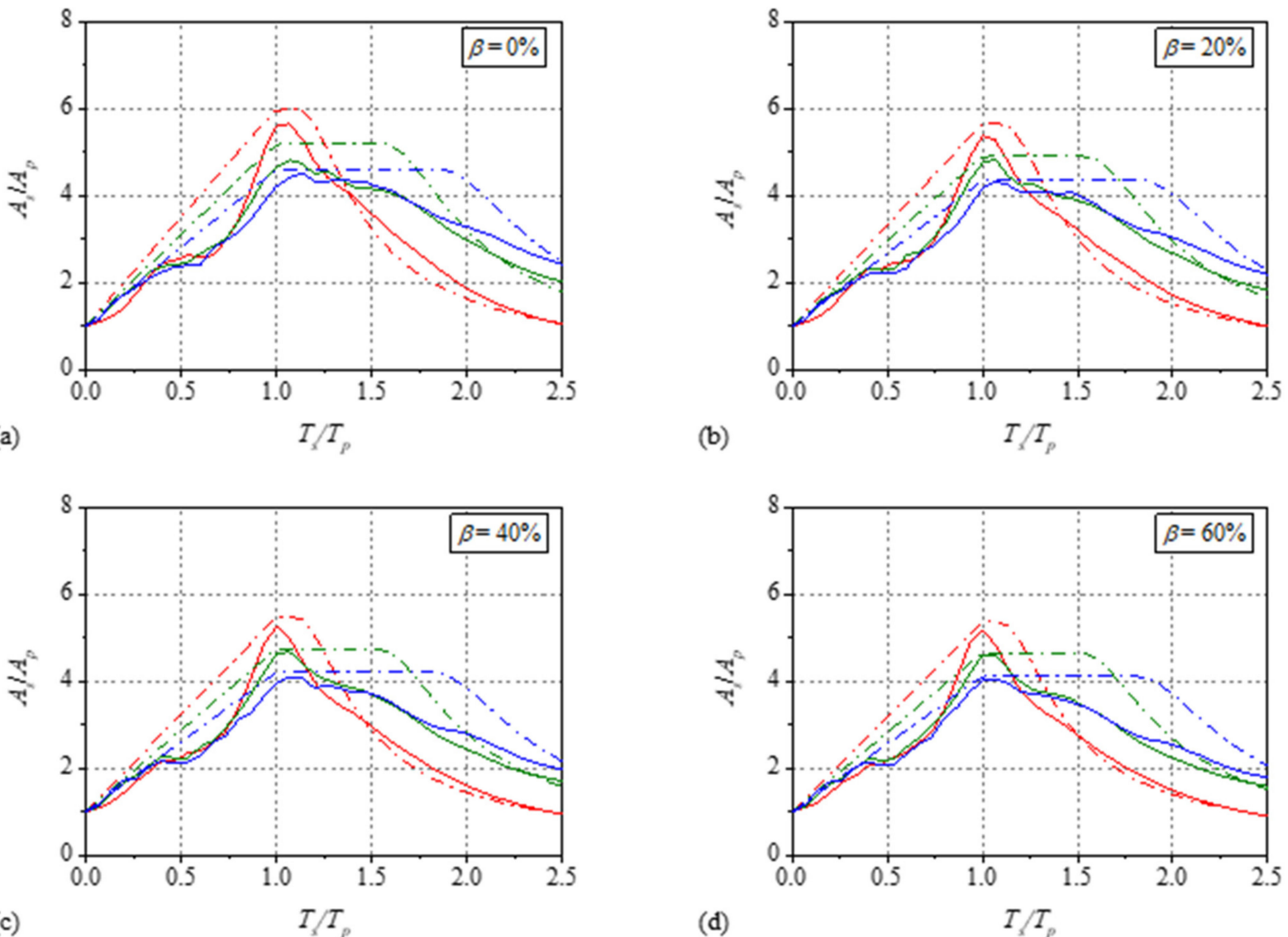

(c)

$T_{S} T_{p}$

(d)
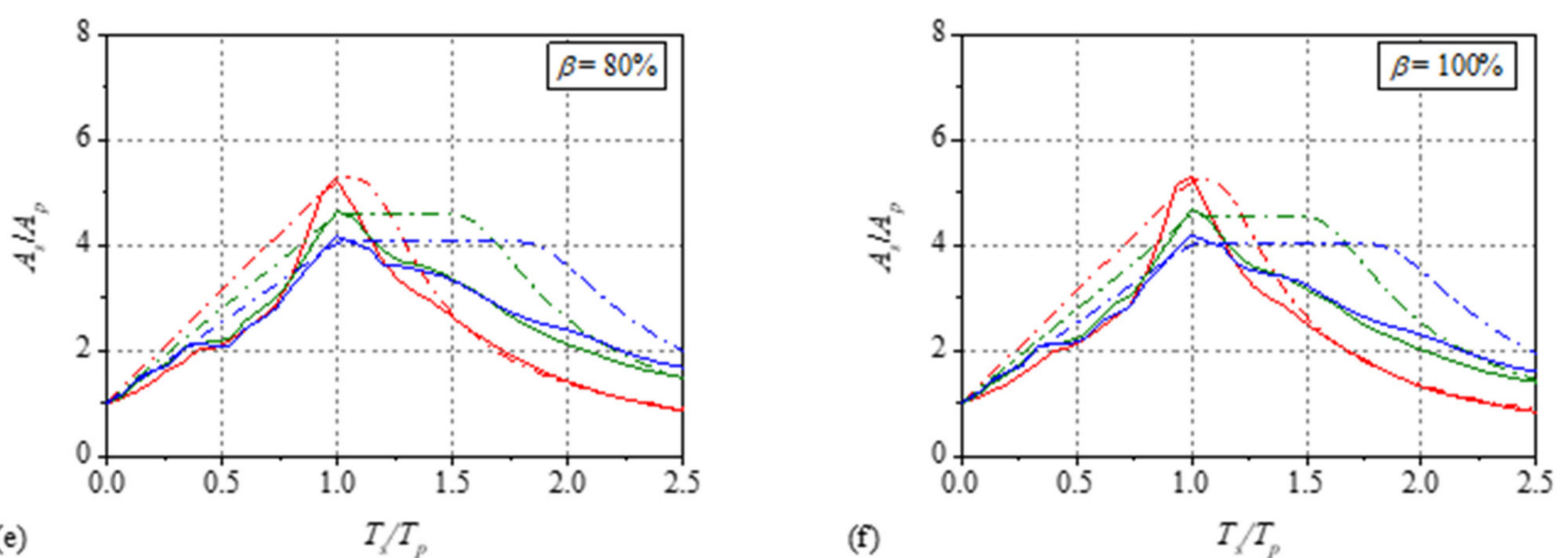

(e)

$T / T_{p}$

(f)

\begin{tabular}{|c|c|c|c|}
\hline$R$ & 2 & 4 & 6 \\
\hline $\begin{array}{l}\text { Eq. (5) - Present A nalysis } \\
\text { NLRHA }\end{array}$ & $\underline{-\cdot-\cdot \cdot}$ & $-\cdot \cdot \cdot \cdot$ & $-\cdot-\left[\begin{array}{ll}0 \\
0\end{array}\right.$ \\
\hline
\end{tabular}

Figure A3. Comparison of the mean normalized floor response spectra from Equation (5) and for a primary structure with initial vibration period $T_{p}=1.5$ s: (a) $\beta=0 \%$; (b) $\beta=20 \%$; (c) $\beta=40 \%$; (d) $\beta=60 \%$; (e) $\beta=80 \%$; and (f) $\beta=100 \%$. 


\section{Appendix B. Existing Direct Methods to Estimate the FRS}

B1. Method of Sullivan et al. [8]

The equation of Sullivan et al. [8] to estimate the FRS for a primary structure with modified Takeda hysteretic model is,

$$
A_{s}\left(T_{p}, R, \beta ; T_{s}, \xi_{s}\right)=A_{p} \begin{cases}1+\frac{T_{s}}{T_{p}}\left(D A F_{\max }-1\right), & 0 \leq T_{s}<T_{p} \\ D A F_{\max }, & T_{p} \leq T_{s} \leq T_{e} \\ D A F_{p r}, & T_{s}>T_{e}\end{cases}
$$

where $D A F_{\max }\left(\xi_{s}\right)=\frac{1}{\sqrt{\xi_{s}}}$ and $D A F_{p r}\left(T_{p} ; T_{s}, \xi_{s}\right)=\frac{1}{\sqrt{\left(1-\frac{T_{s}}{T_{e}}\right)^{2}+\xi_{s}}}$.

B2. Method of Vukobratovic and Fajfar [14]

The equations of Vukobratovic and Fajfar [14] to estimate the FRS for a primary structure with elasto-plastic hysteretic behavior are as follows:

(a) In the pre- and post-resonance region,

$$
A_{s}\left(T_{p}, R, \xi_{p} ; T_{s}, \xi_{s}, S_{e}\right)=\frac{\sqrt{\left\{A_{p}\left(T_{p} / T_{s}\right)^{2}\right\}^{2}+S_{e}\left(T_{s}, \xi_{s}\right)^{2}}}{\left|1-\left(T_{p} / T_{s}\right)^{2}\right|}
$$

where $S_{e}\left(T_{s}, \xi_{s}\right)$ is the value at the specific period and damping ratio in the elastic acceleration spectrum of the ground motion.

(b) In the resonance region,

$$
A_{s}\left(T_{p} ; \xi_{s} ; T_{C}\right)=A_{p} \begin{cases}18\left(1+\xi_{s}\right)^{-0.60}, & T_{p} / T_{C} \leq 1 \\ 18\left(1+\xi_{s}\right)^{-0.60}\left(T_{p} / T_{C}\right)^{-0.20}, & T_{p} / T_{C}>1\end{cases}
$$

where $T_{C}$ is the characteristic period of the ground motion.

\section{References}

1. EERI. Nonstructural Issues of Seismic Design and Construction; Earthquake Engineering Research Institute: Berkeley, CA, USA, 1984.

2. Villaverde, R. Seismic design of secondary structures: State of the art. J. Struct. Eng. (ASCE) 1997, 123, 1011-1019. [CrossRef]

3. Dhakal R., P.; Pourali, A.; Tasligedik A., S.; Yeow, T.; Baird, A.; MacRae, G.; Pampanin, S.; Palermo, A. Seismic performance of non-structural components and contents in buildings: An overview of NZ research. Earthq. Eng. Eng. Vib. 2016, 15, 1-17. [CrossRef]

4. Devin, A.; Fanning, P.J. Non-structural elements and the dynamic response of buildings: A review. Eng. Struct. 2019, 187, 242-250. [CrossRef]

5. Wang, T.; Shang, Q.; Li, J. Seismic force demands on acceleration-sensitive nonstructural components: A state-of-the-art review. Earthq. Eng. Eng. Vib. 2021, 20, 39-62. [CrossRef]

6. CEN. Eurocode 8: Design of Structures for Earthquake Resistance-Part 1: General Rules, Seismic Actions and Rules for Buildings (EN 1988-1); European Committee for Standardization: Brussels, Belgium, 2004.

7. ASCE 7-16. Minimum Design Loads for Buildings and Other Structures; American Society of Civil Engineers (ASCE): Reston, VA, USA, 2017.

8. Sullivan, T.J.; Calvi, P.M.; Nascimbene, R. Towards improved floor spectra estimates for seismic design. Earthq. Struct. 2013, 4, 109-132. [CrossRef]

9. Vukobratović, V.; Fajfar, P. Code-oriented floor acceleration spectra for building structures. Bull. Earthq. Eng. 2017, 15, 3013-3026. [CrossRef]

10. Aragaw, L.F.; Calvi, P.M. Earthquake-induced floor accelerations in base-rocking wall buildings. J. Earthq. Eng. 2021, 25, 941-969. [CrossRef]

11. Kazantzi, A.K.; Vamvatsikos, D.; Miranda, E. The effect of damping on floor spectral accelerations as inferred from instrumented buildings. Bull. Earthq. Eng. 2020, 18, 2149-2164. [CrossRef]

12. Vukobratović, V.; Yeow, T.Z.; Kusunoki, K. Floor acceleration demands in three RC buildings subjected to multiple excitations during shake table tests. Bull. Earthq. Eng. 2021, 19, 5495-5523. [CrossRef]

13. Oropeza, M.; Favez, P.; Lestuzzi, P. Seismic response of nonstructural components in case of nonlinear structures based on floor response spectra method. Bull. Earthq. Eng. 2010, 8, 387-400. [CrossRef] 
14. Vukobratović, V.; Fajfar, P. A method for the direct determination of approximate floor response spectra for SDOF inelastic structures. Bull. Earthq. Eng. 2015, 13, 1405-1424. [CrossRef]

15. Yasui, Y.; Yoshihara, J.; Takeda, T.; Miyamoto, A. Direct generation method for floor response spectra. In Proceedings of the Transactions of the 12th International Conference on Structural Mechanics in Reactor Technology, Stuttgart, Germany, 15-20 August 1993.

16. Welch, D.P.; Sullivan, T.J. Illustrating a new possibility for the estimation of floor spectra in nonlinear multi-degree of freedom systems. In Proceedings of the 16th World Conference on Earthquake Engineering, Santiago, Chile, 9-13 January 2017.

17. Calvi, P.M.; Sullivan, T.J. Estimating floor spectra in multiple degree of freedom systems. Earthq. Struct. 2014, 7, 17-38. [CrossRef]

18. Vukobratović, V.; Fajfar, P. A method for the direct estimation of floor acceleration spectra for elastic and inelastic MDOF structures. Earthq. Eng. Struct. Dyn. 2016, 45, 2495-2511. [CrossRef]

19. Merino R., J.; Perrone, D.; Filiatrault, A. Consistent floor response spectra for performance-based design of nonstructural elements. Earthq. Eng. Struct. Dyn. 2020, 49, 261-284. [CrossRef]

20. Vukobratović, V.; Ruggieri, S. Floor acceleration demands in a twelve-storey RC shear wall building. Buildings 2021, 11, 38. [CrossRef]

21. Kurama, Y.C. Hybrid post-tensioned precast concrete walls for use in seismic regions. PCI Journal 2002, 47, 36-59. [CrossRef]

22. Smith, B.J.; Kurama Y., C.; McGinnis, M.J. Behavior of precast concrete shear walls for seismic regions: Comparison of hybrid and emulative specimens. J. Struct. Eng. (ASCE) 2013, 139, 1917-1927. [CrossRef]

23. Belleri, A.; Schoettler, M.J.; Restrepo, J.I.; Fleishman, R.B. Dynamic behavior of rocking and hybrid cantilever walls in a precast concrete building. ACI Struct. J. 2014, 111, 661-672. [CrossRef]

24. Buddika, H.A.D.S.; Wijeyewickrema, A.C. Seismic performance evaluation of posttensioned hybrid precast wall-frame buildings and comparison with shear wall-frame buildings. J. Struct. Eng. (ASCE) 2016, 142, 04016021. [CrossRef]

25. Shrestha, B.K.; Wijeyewickrema, A.C.; Kono, S. Seismic performance and collapse safety assessment of post-tensioned hybrid precast concrete infill wall-frames and comparison with reinforced concrete infill wall-frames. J. Earthq. Eng. 2021, 1-24, in press. [CrossRef]

26. Priestley, M.J.N.; Calvi, G.M.; Kowalsky, M.J. Displacement-Based Seismic Design of Structures; IUSS Press: Pavia, Italy, 2007.

27. Yang, B.; Lu, X. Displacement-based seismic design approach for prestressed precast concrete shear walls and its application. J. Earthq. Eng. 2018, 22, 1836-1860. [CrossRef]

28. Rahgozar, N.; Moghadam, A.S.; Aziminejad, A. Inelastic displacement ratios of fully self-centering controlled rocking systems subjected to near-source pulse-like ground motions. Eng. Struct. 2016, 108, 113-133. [CrossRef]

29. Zhang, C.; Steele, T.C.; Wiebe, L.D.A. Design-level estimation of seismic displacements for self-centering SDOF systems on stiff soil. Eng. Struct. 2018, 177, 431-443. [CrossRef]

30. Dong, H.; Han, Q.; Du, X.; Liu, J. Constant ductility inelastic displacement ratios for the design of self-centering structures with flag-shaped model subjected to pulse-type ground motions. Soil Dyn. Earthq. Eng. 2020, 133, 106143. [CrossRef]

31. FEMA P695. Quantification of Building Seismic Performance Factors; Federal Emergency Management Agency (FEMA): Washington, DC, USA, 2009.

32. OpenSees. OpenSees. Open system for earthquake engineering simulation. In Computer Program; University of California: Berkeley, CA, USA, 2017. Available online: https:/ / opensees.berkeley.edu/ (accessed on 1 April 2017).

33. Bates, D.M.; Watts, D.G. Nonlinear Regression Analysis and Its Applications; Wiley: New York, NY, USA, 1988.

34. SPSS. IBM SPSS Statistics for Windows; Version 25.0; IBM Corp.: Armonk, NY, USA, 2017. 